\title{
The Role of Illustrations in Following Along with the Events in Fiction
}

\author{
Nasaybah Awajan \\ Hussein Al-Omari \\ Assistant Professor, \\ Middle East University, \\ Airport Rd., Amman, Jordan
}

DOI: https://doi.org/10.36941/ajis-2022-0054

\section{Abstract}

The study explores the effect of using illustrations with written narratives in short stories on the readers who are following along with the events and linking these events together. The study also explores the impact of applying critical thinking skills in using illustrations with the written narrative on readers who are following along with the events of the short story and linking them together. A mixed method was used to answer the questions and obtain the results. The quantitative method was used, where a study sample consisting of 35 students who were asked to submit an exam twice. The first time the exam contained only the written text. However, the second exam contained both the written text and the illustrations from a book. The qualitative method was applied on the same sample of students, where they were interviewed and asked whether the illustrations helped them in answering the questions on the written narrative. Next, they were asked specifically about the six questions which were based on the students' use of their critical thinking skills in linking the provided illustrations with the written narrative. The study concluded by presenting how illustrations have a great effect on the students' following along with the events and understating the main ideas in the narrative story. The results also show that the written text cannot always stand alone, and especially when it comes to young readers because they still lack the experience and the ability to be able to understand things on their own.

Keywords: illustrations, short story, narratives, readers, events

\section{Introduction}

Fiction - whether a novel, a short story or novella - varies in its length, and the number of events and characters that occur within it. Sometimes it may get too difficult for the reader to follow along with the events and chatters that are presented in type of fiction. This is why fiction is sometimes illustrated with pictures. Illustrations are added to these short stories, novels and novellas to help the reader link between the events and follow along with the narrative, which will help in its way to understand the plot of the story. Illustrations have been continuously defined by different scholars depending on their aim and purpose, but usually the purpose of illustrations that are added to stories, whatever the length is, is to give clarity, and more understanding to the written text. So, the aim is to interpret and deliver the written text. Lots of readers, and especially young ones, find it difficult to both understand all of the events and follow along with all the characters in the story; as a 
result, they may find some strategies that they can use to help them follow along with the narrative. For instance, they use strategies like writing down notes, summarizing incidents or perhaps they even start making mind maps for the characters or for the events. This is where the role of illustrations comes into play; they are used in a written narrative to explain what is going on, to follow along, and to enhance the written narrative.

\subsection{Problem of the Study}

Stories are sometimes hard to follow, especially when the story contains a plethora of characters and events. In this case, the reader may be forced to find other strategies to make it easier for him/her to follow along with who is doing what in the story. These tactics might include writing notes, filling in certain tables, or even creating mind maps. To avoid all this extra-added work in order to follow along with the events and link them together when reading a story, the authors of these stories will often add detailed illustrations to these written narratives in order to help the reader.

\section{$1.2 \quad$ Research Questions}

With the use of illustrations in short stories, the sequencing and linking of events become easier and more interesting, especially for children. Without using them, the reader may need to take notes and focus more to understand the story. Hence, the main research questions were formulated as follows:

- What is the effect of using illustrations with the written narrative in short stories on the readers who are following along with the events in short stories and linking the events together?

- What is the effect of applying critical thinking in using illustrations with the written narrative on the readers who are following along with the events in short stories and linking the events together?

\section{Literature Review}

\subsection{Definition of Illustrations}

According to Ibrahim (2013), illustrations can be defined as tools that are represented in the form of pictures and depictions, which have the aim of clarifying the information represented in and associated with any text, whether, informational, literary or others. These illustrations help to deliver the ideas that are written in the text (145-155). Olshansky (2008) adds that illustrations are important to stories and are a vital element in each story. To Olshansky (2008), illustrations are considered to be a visual language that helps the viewer understand and comprehend the written text. This has been common knowledge about illustrations ever since they first started being used in fiction. Ughton \& Willows (1987) add that illustrations help in imagining the events which may add more comprehension about the narrative. This means that illustrations are part of the written language that may work together to contribute more by adding to both comprehension and interpretation. Chu (2018) states that illustrations have developed alongside the written text because they complement one another. Thus, they give better interpretation and understanding, in which illustrations are related to certain graphic techniques, which are directly linked to the text. These graphic techniques enable the reader to read through visual signs instead of just reading written words. Adding to what $\mathrm{Chu}$ (2018) states, by adding illustrations in written stories or narratives in general, the reader has the choice to either follow the images or to follow the written words, or even both. Likewise, Yan (2019) adds that illustrations that are added to fiction could be considered "an artistic language" that delivers information through visual means that provide the reader with detailed interpretation and explanation since it gives visual descriptions of all of these details. 


\subsection{The Use of Illustrations}

Continued studies have been conducted on illustration efficacy in facilitating the comprehension of written texts (Haring, 1982; Donald, 1979, 1983; Haring \& Fry, 1979; Holliday, 1975; Koenke \& Otto, 1969; Royer \& Cable, 1976; Peeck, 1974; Rohwer \& Harris, 1975; Rusted \& Coltheart, 1979a, 1979b; Tennyson, 1978; and Samuels, 1970). The use of pictures and images that are added to stories could be easily "comprehended, remembered, and recalled", unlike the stories that are not presented with pictures or images. The function of illustrations has been considered vital for readers (Schallert, 1980). Illustrations have also been considered as a mnemonic strategy for story comprehension (Haring \& Fry, 1979). Donald (1983) declares that illustrations in this case have the function of facilitating the intended message to be delivered. O'Keefe \& Solman (1987) even believe in the superiority of pictures and images that are added to stories, saying that without these illustrations, the reader cannot reach the same interpretation or comprehension with the written narrative alone.

Maria Nikolajeva and Carole Scott (200o) also argue about how the role of illustrations are important to comprehending the narrative in short stories. Kress (2003) suggests that the presence of illustrations in short stories alongside written narratives may give the reader additional information, which helps the reader in following along with the plot. Michael Benton and Geoff Fox (1985) and Donald Fry (1985) all add that illustrations help the reader build certain images in his/her mind as a part of the reading process which enables him/her to follow along with the events easier. Tessa Dekker et al. (2014) add that research has shown how the building process that the reader creates with the presence of pictures develops over time, is beneficial when reading stories, and supports the reader in the story reading process. David Perkins (1994) adds that readers engage more with illustrations than written texts which results in the integration of the pictures while reading. Berger (1972) and Berger and Mohr (1989) believe in the benefit of linking the image to the written word as well as the importance of this linking. This is the way readers approach any story. The reader gets attracted more to the illustrations rather than the written text. This is due to the fact that readers vary in the reading and comprehension skills they have. Likewise, readers also vary in their levels of knowledge and experience. On this point, Kress (2003) discusses the idea that this reading process or interpretation is guided by the relevant and related illustrations (143-144). Kress and Leeuwen (1996) claim that all modes of communication have their own limitations; however, with a combination of the written words and illustrations, most of these limitations will be fulfilled in which each mode will carry its own "informational load" (Kress, 2003, p. 141). Kress (2003) continues by saying that these modes of communication come together to help the reader reach a better understanding than he/she may reach with the written mode alone since they may carry added information which is not mentioned in details of the text. Peter Hunt (2009) also adds that providing illustrations adds and guides the reader's thinking to other unnoticed incidents. Hunt (2009) also adds that illustrations and wordings together give a complete meaning, while alone they give a separate meaning.

Nikolajeva and Scott (2000) state that the effect of providing illustrations to the written words helps the student understand better (232). Nodelman (1988) thinks that illustrations enable the reader of the short story to think more deeply about the ideas presented in the written text (248). Domin (2007) states that pictures and illustrations were first used by people to tell a story, then written language was integrated and added to the illustrations. Carney and Levin (2002) add that illustrations helped story tellers who transfer their ideas and narratives. This has also motivated authors to provide illustrations in their books (Lai, D. T. $(2021,3)$

Karen M. Feathers \& Poonam Arya (2015) discuss the importance of using images and illustrations along with the written text. Their study reveals images and illustrations contribute to the comprehension and understanding of the students (42 \& 43). Sipe and Brightman (2005) state that young readers not only look at these images, but also unintentionally use them in integration with the written text. Arya and Feathers (2012) also came to the conclusion that young readers benefit from illustrations in such a way that they had the choice of moving between the written text and the illustrations to understand the ideas. According to Arya and Feathers (2012), this supports the 
reader's recognition of words and meaning construction. This means that readers, whatever their age, use illustration in many ways that help them follow along with the events in the story. Mason, Tornatora and Pluchino (2013) and Mason, Pluchino and Tornatora (2013) also state that illustrations are often used in scientific books after seeing its effect of observers or readers. They all state that the reader's integration in both the written and illustrated text has an impact on following along with the details.

Bulkani, at el. (2022) give an example of using such visual aids in presenting the concepts in Math. They justify this by saying that using aids may make the students enjoy mathematics and make it more effective. Pierce (2010) states that illustrations lead to the reader's engagement in the written text and narratives. Murguia (2013), Downing (2013) and Sloat (2013) all agree on the fact that illustrations enable readers to feel the words. This ensures that words and images are not used to replace the statement of the story, but rather add to each other (Salisbury, 2004; Paul, 2009; Dils, 2009). Hladikova (2014) states that the most important contribution of illustrations is that they complement and parallel the narrative presented in the written text. Kim at el. (2017) state that integrating visual art may enhance the readers' critical thinking.

\section{Method}

\subsection{Research Design and Flow}

A mixed approach was applied to answer the questions of the study. First, the researchers used the quantitative approach, in which two exams were prepared with the same questions. The first exam that was given to the students contained a short story, but the illustrations of the story were hidden from the students. In other words, the students were only provided with the written text. The second exam given to the students consisted of both the written text and the illustrations of the story. The exam aimed to show whether the students would be able to answer questions about the story without having the illustrations in front of them. The exam also aimed at finding out whether or not the students will have the same answers whether they were provided with illustrations or not. The exam consists of 42 questions; six of the questions required the students to use their critical thinking skills in answering the questions even while they were also provided with the illustrations. All of the questions highlighted and focused on the sequence of the incidents and events. The researchers then used the qualitative method in an interview conducted with the same students where they were asked whether the illustrations helped them in answering the questions on the written narrative or not. Then, they were asked specifically about the six questions that were based on their critical thinking skills in linking the provided illustrations with the written narrative.

\subsection{Population and Sample}

The study was conducted on Thirty-five third-grade students, who were chosen to respond to a True/False question exam on a short story. The third-grade students were specifically chosen as they matched the level of the story chosen for the study. The sample of students was taken from one class, since the students in each grade are distributed according to their background knowledge, achievement level and needs.

\subsection{Data Analysis Technique}

The analysis of the study aimed at statistically defining the significant difference $(\alpha=0.05)$ in-group performance in the exam, which is without illustrations, and the exam, which is with illustrations. Both exams included 42 questions. To answer the first question of the study, "What is the effect of using illustrations with the written narrative in short stories on the readers who are following along with the events in short stories and linking the events together?" A t-test known as the Paired Sample t-test was used for two correlated samples. 
For the six questions that were based on the students' critical thinking, the analysis aimed at statistically defining the significant differences $(\alpha=0.05)$ in-group performance in relation to the students' critical thinking skills in both exams - the first with illustrations and the second without illustrations. To answer the second question of the study, "What is the effect of applying critical thinking in using illustrations with the written narrative on the readers who are following along with the events in short stories and linking the events together?" A t-test was used for two correlated samples, known as the Paired Sample t-test.

\section{Findings}

Results of the exam with and without illustrations. Table No. 1 shows the results related to the question "What is the effect of using illustrations with the written narrative in short stories on the readers who are following along with the events in short stories and linking the events together?"

\section{Table 1:}

\begin{tabular}{|l|c|c|c|c|c|c|}
\hline & $\mathrm{N}$ & Mean & Std. Deviation & T - Vale & df & Sig. \\
\hline Exam without Illustrations & & $\mathbf{2 2 . 5 7}$ & 6.13 & 17.92 & 34 & 0.00 \\
\hline Exam with Illustrations & 35 & 41.00 & 1.41 & & & \\
\hline
\end{tabular}

Results of the questions that need critical thinking for linking the illustrations with the written narrative. Table No. 2 shows the results of the question, "What is the effect of applying critical thinking in using illustrations with the written narrative on the readers who are following along with the events in short stories and linking them together?"

Table 2:

\begin{tabular}{|l|c|c|c|c|c|c|}
\hline & $\mathrm{N}$ & Mean & Std. Deviation & $\mathrm{T}$ - Vale & df & Sig. \\
\hline Exam without Illustrations & & 2.34 & 0.91 & & & o.oo \\
\hline Exam with Illustrations & 35 & 5.60 & 0.50 & 21.75 & 34 & \\
\hline
\end{tabular}

It is noted from the results of the analysis that there are statistically significant differences in favor of the exam with illustrations where the mean was higher compared to the exam without illustrations.

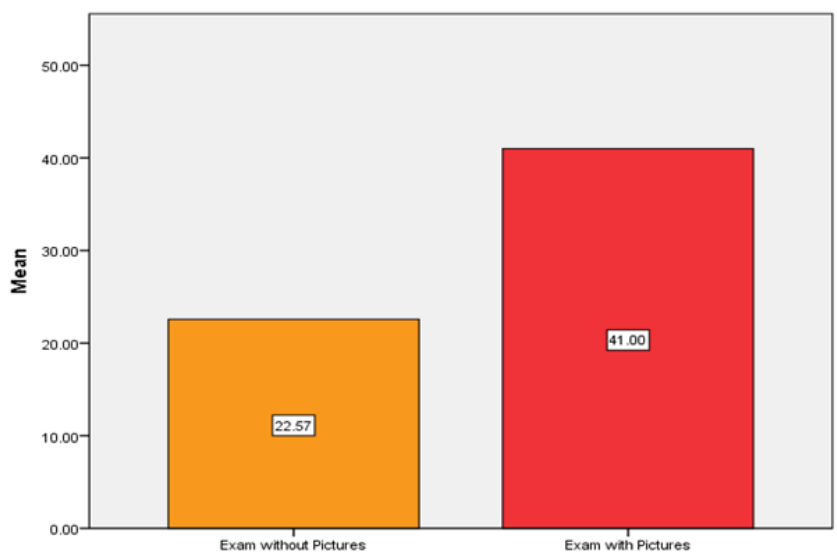

Figure 1: shows the values of the means for the performance 
It is noted from the results of the analysis that there are statistically significant differences in critical thinking in favor of the exam with illustrations where the mean was higher compared to the exam without illustrations.

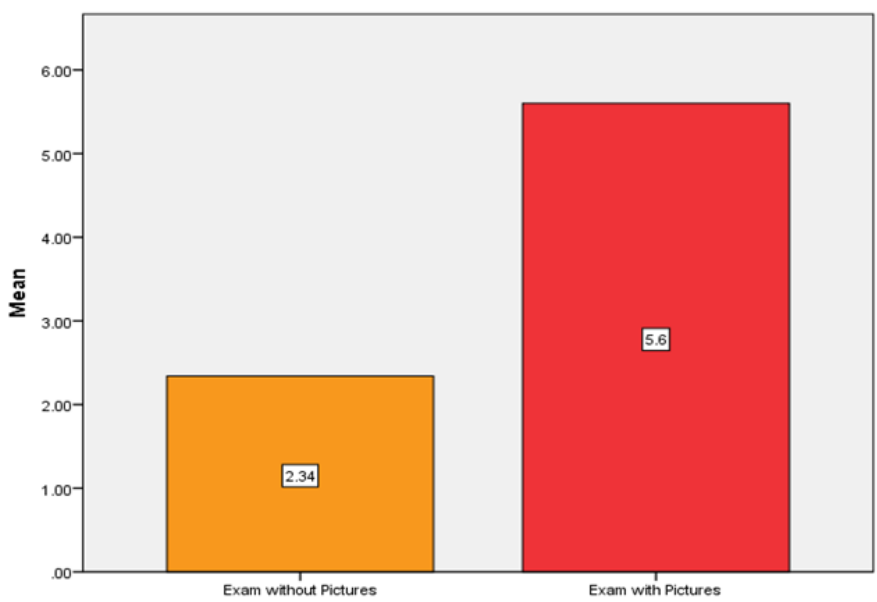

Figure 2: shows the values of the means for the performance (Critical Thinking)

The Results of the interview showed that 90\% of the students think that the illustrations helped them in following along with the events which made it easier for them to answer the questions. On the other hand, $5 \%$ of the students thought that most of the illustrations helped them in following along with the events. The rest are $5 \%$ of the students, who thought that some of the illustrations did not really help them in following along with the events. These percentages are illustrated in the Figure 3.

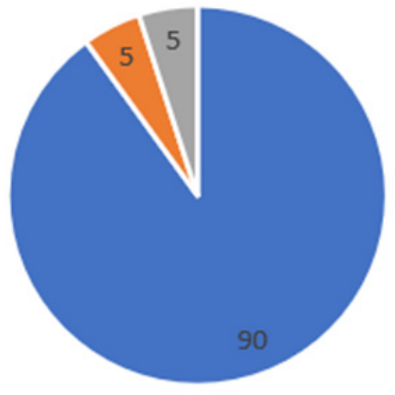

Figure 3: The Effect of Illustrations

For the six questions that are based on the students' critical thinking skills in linking the provided illustrations with the written narrative, the students who answered all of these questions were also interviewed. $98 \%$ of the students said that they had to think harder when linking the illustrations to the written narrative in answering these questions. At the same time, $2 \%$ of the students said that they were not able to answer the questions on the narrative even when providing them with the illustrations. The students' answers are illustrated in Figure (4). 


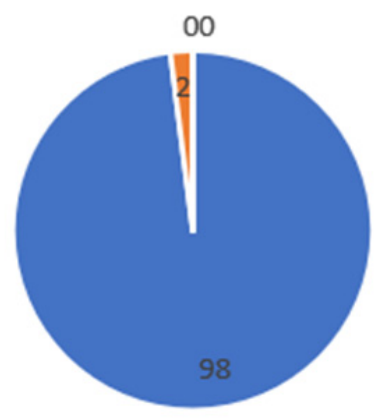

Figure 4: Results of the Six Questions

\section{Analysis and Conclusion}

Going through the results that are shown in the figures, it could be generally noticed that illustrations have a great effect on the students being able to follow along with the events and understanding the main ideas in the narrative story. The results also show that the written text cannot always stand alone, especially when the readers are young, which means that they still lack the experience and the ability to understand things on their own. There were 20 illustrations in the story that were chosen for the study which are linked to the written narrative. This study shows that the provided illustrations make a vital contribution to the understanding of the students and enhanced their ability to follow up with the events presented in the short story. This is because the story was long for the students and the illustrations made it easier for the students to overcome this obstacle.

As can be noticed in Figure 1, the average number of students who answered the questions is 22. 57 out of 41. These students were not able to understand the written text and follow along with the events presented in the narrative because they were not provided with the illustrations. Some students may overcome this obstacle by writing down some notes or drawing mind maps, but if they were provided with more time. This means that the students were not able to answer the questions without linking the narrative events to the illustrations of these narratives.

On the other hand, when the students were given the same exam on the same narrative text, only this time by including the illustrations provided by the author, the average raised to 41 out of 42 . This increase, presented in Figure 2, directly points out the fact that illustrations were added to the exam this time, so when the students were given and provided with the illustrations, their marks increased by a large number. This shows the effect of illustrations on their understanding. Illustrations in this way may help the students understand the story and follow up with the events without writing notes. This is important for those at the age of the students of the sample that were chosen for the study. In this case, illustrations contributed to the written text and filled in the gaps of the students' understanding of the written text. This is similar to the argument of many scholars such as Karen M. Feathers \& Poonam Arya (2015). This also goes with what Sipe and Brightman (2005) argue, which is that young readers benefit a great deal from illustrating the narrative text which works in integration with the written text. Illustrations help the young readers move between the images and the written text to understand the ideas presented; this goes with what Arya and Feathers (2012), Mason, Tornatora and Pluchino (2013) and Mason, Pluchino and Tornatora (2013) declare.

As mentioned before, six questions were asked on the written text; however, the first exam did not provide the students with the illustrations. They were then given the exam again, but this time with the illustrations. These questions were based on the students' critical thinking skills in linking the written text with the illustrations provided. As could be noticed from Figure 2, the average of the students' answers of these six questions without providing the students with the illustrations on the 
narrative text, is (2.34) out of 6. This means that even when the students are asked to apply higher levels of thinking, they need to have tools to support this thinking; in such cases, they can be provided by illustrations. This could be enhanced due to the fact that when they were given the illustrations, the students answered these questions. This appears in Figure 2, where the average increased from (2.34) to (5.6). This could be interpreted in a way that whatever the question is, the reader will unintentionally move to the illustrations if provided with the written text, looking for things to link with the narrative text. These critical thinking questions require more linking to the illustrations than the other questions.

These results go with what Kress (2003) state about how the means of communication complement each other saying that sometimes the illustrations may carry more clarifications and details that are not clear in the written text and that would help the reader understand better and follow the details better. The results are also similar to what Hunt (2009) states, which is that illustrations added to written texts may add to and guide the reader's thinking to other embedded and unmentioned details and incidents.

The researchers tried to enhance the role of illustrations in asking the students and interviewing them on what really made their understanding better and whether the illustrations really helped them in answering the questions. Figure (3) shows that $90 \%$ of the students think that the illustrations helped them in following along with the events, which made it easier for them to answer the questions. On the other hand, $5 \%$ of the students thought that most of the illustrations helped them in following along with the events. The rest, which are $5 \%$ of the students, thought that some of the illustrations did not really help them in following along with the events. This shows how the readers - the students in the case of the current study - really benefit from having illustrations. This resembles what Hunt (2009) argues on, which is that illustrations and wordings together give a complete meaning, while they alone give separate meaning. This is not just shown in the exams given to the students, but also they all mentioned the role of illustrations and how it made it easier for them to answer the questions they were asked.

This could be also applied to the six questions that are based on critical thinking. The students then were specifically asked about these questions. They said that they really had to look at the illustrations when answering and trying to link what they read from the narrative text and the illustrations to be able to follow the sequence of the events and the incidents. Figure 4 shows that $98 \%$ of the students said that they had to think harder when linking the illustrations to the written narrative in answering these questions. At the same time, $2 \%$ of the students said that they were not able to answer the questions on the narrative even with providing them with the illustrations. The students show how they were pleased to have the illustrations and how they panicked and were stressed while answering the exam without illustrations. This follows what many scholars state such as Nikolajeva and Scott (200o) and Nodelman (1988), when they posit that providing illustrations with written words gives more effect on the understanding of the students and that illustrations enable the reader of the short story to think more deeply of the ideas presented in the written text. This also resembles what Kim at el. (2017) state on how using visual art may enhance the readers' critical thinking.

\section{Limitations}

The study is limited to the sample that was chosen for the study from the population of Grade 3 from a private school in Amman. The results cannot be generalized for all the students in the third grade in Jordan or in any other country for that matter. The results are also limited to the short story that was chosen for the study and to the type of exam given to the students. The results of the study are limited to the time in which the study was conducted which just happened to be at a time when people are exposed to the circumstance and conditions of COVID-19. As a result, this made it hard to enlarge the sample according to the rules of schools in Jordan because of the pandemic and subsequent quarantine. 


\section{Recommendations}

\subsection{General}

The researchers recommend the following points for future research:

1. Conducting more studies on samples from different ages and backgrounds.

2. Conducting the same study on bigger samples.

3. Conducting the same study on other genres of fiction such as novels and novellas.

4. Conducting the same study in public schools in Jordan.

\subsection{Specific}

1. The integration of illustrations in fiction, especially those for young readers.

2. Adding illustrations to educational books for students.

3. Applying strategies for students to link between illustrations and written texts.

4. Focusing on the illustrations of narratives that would help young readers more in following along with the events.

\section{Acknowledgment}

We would like to thank the Middle East University in Amman, Jordan, for their financial support granted to cover the publication fee of this research article.

\section{References}

Aggleton, J. (2017). "What is the use of a book without pictures?" An exploration of the impact of illustrations on reading experience in a monster calls. Children's Literature in Education, 48(3), 230-244.

Arya, P., \& Feathers, K. (2012). Reconsidering children's readings: Insights into the reading process. Reading Psychology, 33, 301-322.

Benton, M., \& Fox, G. (1985). Teaching Literature: Nine to Fourteen Oxford: Oxford University Press.

Berger, J. (1972). Ways of Seeing London: Penguin.

Berger, J., \& Mohr, J. (1989). Another Way of Telling Cambridge: Granta.

Bulkani., Fatchurahman, M., Adella, H., \& Setiawan, M. A. (2022). Development of animation learning media based on local wisdom to improve student learning outcomes in elementary schools. International Journal of Instruction, 15(1), 55-72.

Carney, R. N., \& Levin, J. R. (2002). Pictorial illustrations still improve students' learning from text. Educational Psychology Review (14), 5-26.

Chu, Y. (2018). Analysis of the Application of Illustration Art in Graphic Design. In 2018 3rd International Conference on Politics, Economics and Law (ICPEL 2018) (pp. 539-541). Atlantis Press).

Dekker, T., Mareschal, D., Johnson, M, H., \& Sereno, M, I. (2014). Picturing Words? Sensorimotor Cortex Activation for Printed Words in Child and Adult Readers. Brain and Language, 139, 58-67.

Dils, T. E. (2009) You Can Write Children's Books. 2nd edn. Cincinnati: Writer's Digest Books.

Domin. (2007). On application of visuals in teaching English: Selected Issues. International conference KnowledgeBased Organization, 356-361.

Donald, D. R. (1979). Effects of illustrations on early oral reading accuracy, strategies and comprehension. British Journal of Educational Psychology, 49(3), 282-289.

Donald, D. R. (1983). The use and value of illustrations as contextual information for readers at different progress and development levels. British Journal of Educational Psychology, 53, 175-185.

Fry, D. (1985). Children Talk About Books: Seeing Themselves as Readers Milton Keynes: Open University Press.

Haring, M. J. (1982). Picture enrichment of delayed recall: Support from a unique source. British Journal of Educational Psychology, 52, 104-108.

Haring, M. J., \& Fry, M. A. (I979). Effect of pictures on children's comprehension of written text. Educational Communication and Technology Journal, 27, 185-19o.

Hladikova, H. (2014). Children's Book Illustrations: Visual Language of Picture Books. CRIS Bulletin /o1. 
Holliday, W. G. (1975). The effects of verbal and adjunct pictorial-verbal information in science instruction. Journal of Research in Science Teaching, 12, 77-83.

Hunt, P. (2009). Introduction. In Sophie Hallam (Ed.), Illustrated Children's Books (pp. 9-10). London: Black Dog Publishing.

Ibrahim, R., A. (2013). The unified identity of illustrations in the Geographical Knowledge Encyclopedia. Ph.D. Thesis, Faculty of Fine Arts, Alexandria University.

Karen, M. F. \& Poonam A. Exploring Young Children's Patterns of Image Use in a Picturebook. Language and Literacy Volume 17, Issue 1, 2015. 41-62.

Kim, K., Wee, S., Han, M., Sohn, J., Hitchens, C., \& Walker. (2017). Enhancing Children's Art Appreciation and Critical Thinking Through a Visual Literacy- Based Art Intervention Programme. International Journal of Education Through Art. 13(3), 317-332.

Koenke, K., \& Otto, W. (1969). Contribution of pictures to children's comprehension of the main idea in reading. Psychology in the Schools, 6, 298-302.

Kress, G, \& Van L. T. (1996). Reading Images: The Grammar of Visual Design London: Routledge.

Kress, G. (2003). Interpretation or Design: From the World Told to the World Shown. In Morag Styles \& Eve Bearne (Eds.), Art, Narrative and Childhood (pp. 137-153). Staffordshire: Trentham Books Limited.

Lai, D. T. (2021). A study on benefits of using illustrations (pictures, real object, etc.) in learning English vocabulary of non-English major students at Ho Chi Minh City University of Food Industry (HUFI).

Nikolajeva, M., \& Scott, C. (200o). The Dynamics of Picturebook Communication. Children's Literature in Education, 31(4), 225-239.

Nodelman, P. (1988). Words About Pictures: The Narrative Art of Children's Picture Books Georgia: University of Georgia Press.

O'Keefe, E. J., \& Solman, R. T. (1987). The influence of illustrations on children's comprehension of written stories. Journal of reading behavior, 19(4), 353-377.

Olshansky, B. (2008). The power of pictures: Creating pathways to literacy through art, grades K-6. John Wiley \& Sons.

Paul, A. W. (2009). Writing Picture Books. Cincinnati: Writer's Digest Books. Pierce, T. (2010) 'Five Reasons Why Children NEED Picture Books', Terry Pierce: Children's Author, 12 October. Available at: http://terrypierce.blogspot.cz/2010/10/five-reasons-why-children-need-picture.html (Accessed: 11 October 2013).

Peeck, J. (1974). Retention of pictorial and verbal content of a text with illustrations. Journal of Educational Psychology, 66, 880-888

Rohwer, W. D., \& Harris, W. J. (1975). Media effects on prose learning in two populations of children. Journal of Educational Psychology, 67, 651-657.

Royer, J. M., \& Cable, G. W. (1976). Illustrations, analogies, and facilitative transfer in prose learning. Journal of Educational Psychology, 68, 205-209.

Rusted, J., \& Coltheart, V. (1979a). The effect of pictures on the retention of novel words and prose passages. Journal of Experimental Child Psychology, 28, 516-524.

Rusted, J., \& Coltheart, M. (1979b). Facilitation of children's prose recall by the presence of pictures. Memory and Cognition, 7, 354-359.

Salisbury, M. (2004) Illustrating Children's Books. New York: Barron's Educational Series, Inc.

Sipe, L. R., \& Brightman. A. (2005). Young children's visual meaning-making during read aloud of picture storybooks. In B. Maloch, J. Hoffman, D. Schallert, C. Fairbanks, \& J. Worthy (Eds). 54th Yearbook of the National Reading Conference (pp. 349-361). Oak Creek, WI: National Reading Conference.

Tennyson, R. D. (1978). Pictorial support and specific instructions as design variables for children's concept and rule learning. Educational Communication and Technology Journal, 26, 291-299.

Ughton, H., \& Willows, D. (1987). The Psychology of Illustration. 2, 159-186.

Yan, Z. (2019). Discussion on Significance and Effect of Illustration Art in Graphic Design. no. Etmhs, 304-6) 